\title{
6 GHz Microstrip Patch Antennas with PEDOT and Polypyrrole Conducting Polymers
}

\author{
Akhilesh Verma ${ }^{1}$, Bo Weng ${ }^{2}$, Roderick Shepherd ${ }^{2}$, Christophe Fumeaux ${ }^{1}$, Van-Tan Truong ${ }^{3}$, \\ Gordon G. Wallace ${ }^{2}$, Bevan D. Bates ${ }^{1,3}$
}

\begin{abstract}
Two $6 \mathrm{GHz}$ microstrip patch antennas made from conducting polymers with relatively low DC conductivity such as PEDOT $(10000 \mathrm{~S} / \mathrm{m})$ and PPy $(2000 \mathrm{~S} / \mathrm{m})$ are presented. The performance of these patch antennas is compared with a similar copper patch antenna. The results indicate that it is possible to obtain reasonable performance albeit with modest radiation efficiencies. The PEDOT antenna achieved a maximum gain of $2.2 \mathrm{~dB}$, while the PPy antenna reached a gain of $3.8 \mathrm{~dB}$, as against $6.0 \mathrm{~dB}$ for a corresponding $\mathrm{Cu}$ patch antenna The results confirm the potential of polymer materials for microwave antennas and suggest that CPs may be of use in other passive microwave circuit applications.
\end{abstract}

\section{INTRODUCTION}

Recently there has been a growing interest in exploiting conducting polymers (CP) for planar antennas [1-5]. The motivation for building an antenna using CPs is to exploit the plastic-like mechanical properties and processability of these materials. A further motivation is to explore some attractive properties such as the manipulation of electrical properties of CPs through an external stimulus or a controlled ion exchange process. This last property potentially makes CPs attractive options for applications where re-configurable antenna structures are beneficial. In this paper we present $\mathrm{CP}$ based microstrip antennas with stand-alone polypyrrole (PPy) film and inkjet printed PEDOT-PSS (Poly 3, 4ethylenedioxthiophene Poly Styrene Sulfonate) as radiating patches. The paper highlights the possibility of using PPy and PEDOT as a resonant patch on a microstrip antenna. This research is part of our work on re-configurable antennas using CPs. This investigation is a step towards a better understanding of the numerical simulation, design and fabrication of antennas based on these materials for various potential applications.

\section{CP FILM PREPARATION}

The CP films used for making the resonant patches in this microstrip antenna design were made from two different types of CPs and these films were obtained from two completely different processes. The PPy film was prepared through a process of electrochemical polymerization, while the PEDOT film was obtained by printing commercially available PEDOT ink on an Arylite $^{\mathrm{TM}}$ substrate. These CP films have been used for fabricating $6 \mathrm{GHz}$ microstrip patch antennas. A patch made from $7 \mu \mathrm{m}$ thick PEDOT film (DC conductivity - $10000 \mathrm{~S} / \mathrm{m}$ ) printed on a $200 \mu \mathrm{m}$ Arylite ${ }^{\mathrm{TM}}$ substrate was pasted on Rogers Corp.'s Ultralam ${ }^{\circledR} 2000$ substrate. Similarly, a PPy antenna was fabricated with a patch made from a $90 \mu \mathrm{m}$ stand-alone PPy film (DC conductivity - $2000 \mathrm{~S} / \mathrm{m})$. An identical copper $(\mathrm{Cu})$ patch antenna on Ultralam ${ }^{\circledR} 2000$ was also fabricated for validating the simulation of $\mathrm{CP}$ antennas and comparing their performance

\subsection{Polypyrrole film}

The PPy film for the antenna patch was obtained from The Defence Science and Technology Organization (DSTO) in Melbourne, Australia. It was prepared in accordance with the procedure indicated by Truong et al. [6]; i.e. through electrochemical polymerization in an aqueous solution. Sodium $p$ toluene sulphonate ( $p$-TS) was used as the dopant.

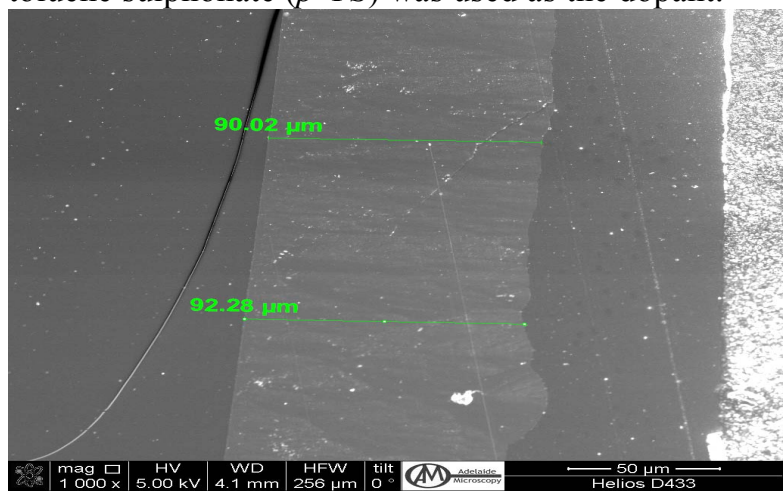

Figure 1: SEM measurement of PPy film thickness

Electrodes of stainless steel were used for growing the film in a nitrogen environment. The films obtained by the above procedure were $90 \mu \mathrm{m}$ thick

\footnotetext{
${ }^{1}$ School of Electrical and Electronics Engineering, University of Adelaide,North Tce, Adelaide,SA 5005,Australia, e-mail: akhilesh@eleceng.adelaide.edu.au , tel.: +61 88303 4707, fax: +61 883034360

${ }^{2}$ Intelligent Polymer Research Institute (IPRI), University of Wollongong, Squires Way, Fairy Meadow, NSW 2519 ,Australia, e-mail: rods@uow.edu.au, tel.: +61 2 42213127, fax: +61 242213114.

${ }^{3}$ Defence Science and Technology Organisation, Adelaide, SA, Australia, e-mail: bevan.bates@dsto.defence.gov.au , tel.: +61 873896636 , fax: +61 873895254.
} 
and were washed in acetonitrile/water (1:1 solution) to remove excess dopant. The films were then allowed to dry. Using the four-probe technique, the DC conductivity of the film sample was measured as $2000 \mathrm{~S} / \mathrm{m}$. The thickness of the PPy film was accurately measured using a Scanning Electron Microscope (SEM) Philips XL 30 (Figure 1).

\subsection{PEDOT film}

A PEDOT film of $7 \mu \mathrm{m}$ thickness printed on a 200 $\mu \mathrm{m}$ Arylite $^{\mathrm{TM}}$ substrate was obtained from The Intelligent Polymer Research Institute (IPRI), University of Wollongong. The PEDOT film was printed on the Arylite ${ }^{\mathrm{TM}}$ substrate using a commercially available PEDOT ink called Clevios $P^{T M}$ [7]. The printed PEDOT film had a DC conductivity of $10000 \mathrm{~S} / \mathrm{m}$. A Dimatix 2800 inkjet printer was used for printing the Clevios PTM on the substrate. The printing process is capable of printing very thin films (few nanometres) of Clevios PTM. However, in order to achieve film thicknesses in micro-metres, several layers have been printed on each other resulting in $7 \mu \mathrm{m}$ Clevios $\mathrm{P}^{\mathrm{TM}}$ thin films. The thickness of the printed film was measured accurately using a contact profiler.

\section{ANTENNA DESIGN}

Three nearly identical antennas were fabricated on $1.8 \mathrm{~mm}$ thick Roger Corp's Ultralam 2000 substrate. The first antenna was made by pasting a patch made from $90 \mu \mathrm{m}$ thick PPy standalone film. A schematic of the antenna is shown in Figure 2(a).

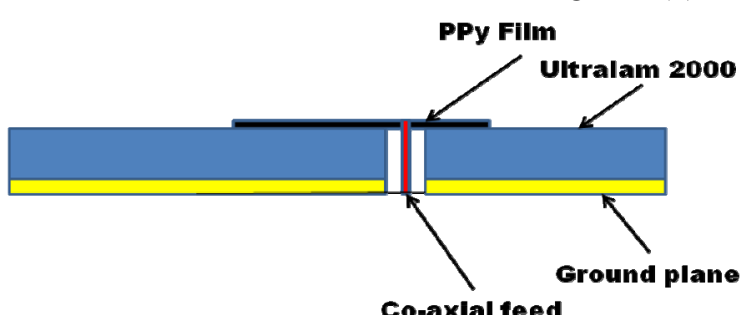

(a)

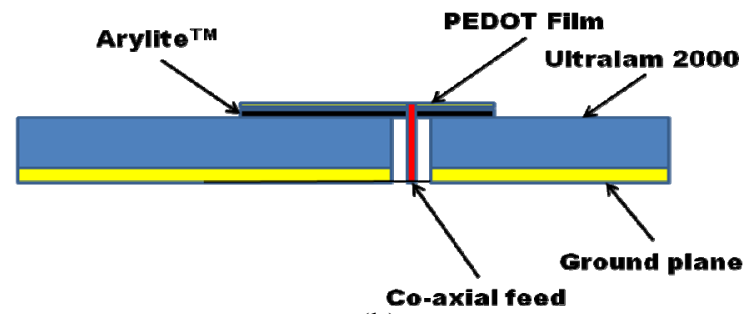

(b)

Figure 2: A schematic of (a) PPy and (b) PEDOT patch antennas

Similarly, for the second antenna, a $7 \mu \mathrm{m}$ PEDOT film patch printed on Arylite ${ }^{\mathrm{TM}}$ substrate was pasted on Ultralam $2000^{\mathrm{TM}}$ substrate. A schematic of the
PEDOT antenna is shown in Figure 2(b). An identical copper $(\mathrm{Cu})$ patch antenna was fabricated for validation of the simulation and for direct comparison of the relative performance of these patch antennas. A good match between the simulation and measured parameters was obtained for Ultralam $2000^{\mathrm{TM}}$ permittivity of 2.45 (Figure 3 ).

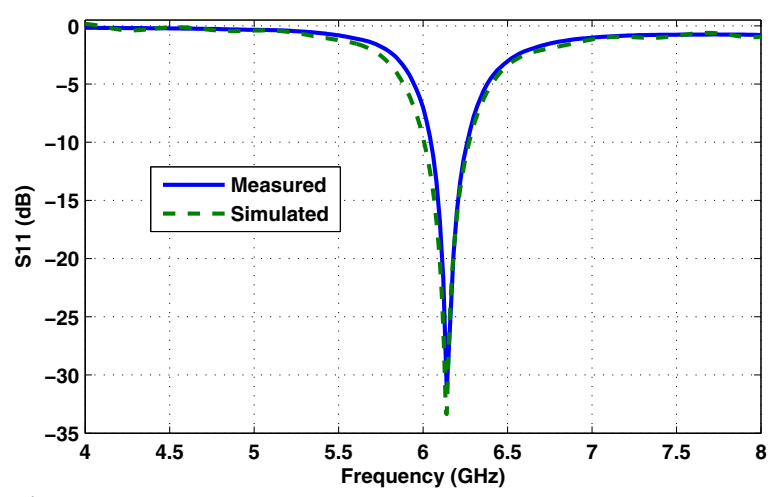

Figure 3: Simulated and measured S11 for a $\mathrm{Cu}-$ patch antenna on Ultralam $2000^{\mathrm{TM}}$ substrate.

\subsection{Simulations and design optimization}

The antenna designs were optimized for good impedance match. The design parameters for the microstrip patch antennas are indicated in Table 1.

\begin{tabular}{|l|c|c|c|}
\hline Parameter & Cu & PPy & PEDOT \\
\hline Substrate & \multicolumn{3}{|c|}{ Ultralam 2000 } \\
\hline - Thickness & \multicolumn{3}{|c|}{$1.8 \mathrm{~mm}$} \\
\hline • Dimension & \multicolumn{3}{|c|}{$80 \mathrm{x} 80 \mathrm{~mm}$} \\
\hline • permittivity & \multicolumn{3}{|c|}{2.45} \\
\hline Patch & $17 \mu \mathrm{m}$ & $90 \mu \mathrm{m}$ & $7 \mu \mathrm{m}$ \\
\hline$\bullet$ Thickness & $5.8 \times 10^{7}$ & 2000 & 10000 \\
\hline $\begin{array}{l}\text { - DC Conductivity } \\
\text { (S/m) }\end{array}$ & 14.16 & 14.0 & 14.0 \\
\hline$\bullet$ Length (mm) & 12.9 & 12.9 & 12.9 \\
\hline$\bullet$ Width (mm) & 1.28 & 3.25 & 3.63 \\
\hline $\begin{array}{l}\text { - Feed point (off- } \\
\text { center) (mm) }\end{array}$ & & \\
\hline
\end{tabular}

Table 1: Optimized design parameters of microstrip patch antennas.

The effect of the patch thickness for less conductive materials (such as PPy/PEDOT) is an important consideration in this design. Most antenna designers would consider a couple of skin depths thickness for PPy/PEDOT patch as essential. The skin depths for the patch antennas at $6 \mathrm{GHz}$ are $145 \mu \mathrm{m}$ for PPy, 65 $\mu \mathrm{m}$ for PEDOT and $0.85 \mu \mathrm{m}$ for $\mathrm{Cu}$. It is evident that the thicknesses of PPy and PEDOT patches are far less than one skin depth. In contrast, the $\mathrm{Cu}$ patch thickness is about 20 times its skin depth. The patches were simulated as impedance sheets using HFSS $^{\mathrm{TM}}$, to take into account the effect of patch thickness. 


\subsection{Antenna fabrication}

Fabrication of the microstrip antenna using the freestanding PPy patch proved challenging because of the mechanical properties of the material. The PPy film is very delicate and tends to shear along the cut edges. This therefore makes it hard to cut the film to exact patch size or drill holes using computer-assisted tools. The PPy patch was cut to the desired size by hand using a suitable template. Since a systematic fabrication error within tolerances affected the realisation of the optimised parameters, the simulation was later adjusted according to actual dimensions of the fabricated devices. On analysis of the patches cut by hand it emerged that the patch sizes where about 0.1 to $0.2 \mathrm{~mm}$ under the optimised design values; the effect of which is evident in the resonant frequency shifting slightly above $6 \mathrm{GHz}$. The actual antenna parameters achieved are listed in Table 2

\begin{tabular}{|l|c|c|}
\hline Parameter & PPy & PEDOT \\
\hline Patch & & \\
\hline$\bullet$ Length (mm) & 13.9 & 13.85 \\
\hline$\bullet$ Feed point (off center) (mm) & 3.2 & 3.5 \\
\hline
\end{tabular}

Table 2: Realised antenna parameters.

\section{RESULTS}

CPs also exhibit dispersion in their electrical conductivity with frequency [8-10]. Therefore, the measured results differed from the simulated results not only due to fabrication errors, but also due to dispersion in electrical conductivity. Figures 4 and 5 show the measured reflection coefficient for the two PC antennas, together with three sets of simulated results. The optimal design curves correspond to the simulation results achieved before fabrication. The second pair of simulation curves represent the results after correction of the fabrication errors, which corrects the small frequency shift of the resonance. Finally, a nearly perfect match to measurements was obtained in the third pair of simulation curves through adjustment of electrical conductivity of the films. The measured DC surface resistivity and observed DC surface resistivity at $6 \mathrm{GHz}$ for the PPy and PEDOT films are shown in Table 3, and provide evidence of the dispersive increase in conductivity for the $\mathrm{CP}$ materials with increasing frequencies.

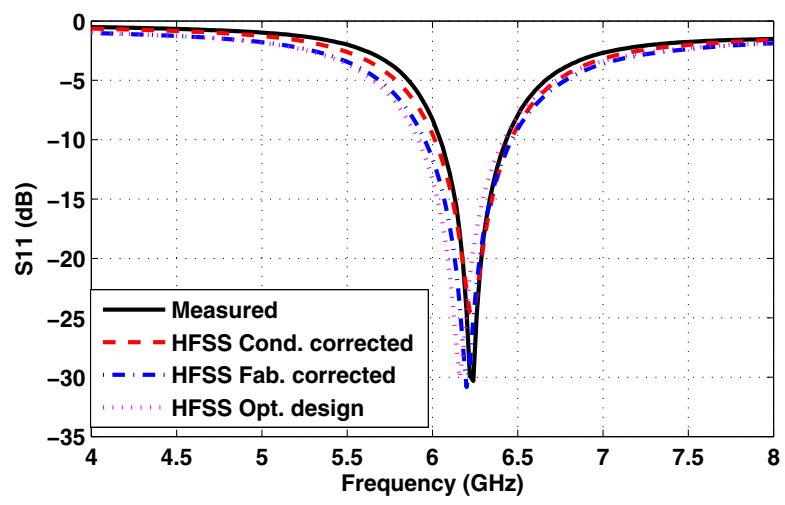

Figure 4: Simulated and measured S11 for a PPypatch antenna on Ultralam $2000^{\mathrm{TM}}$ substrate

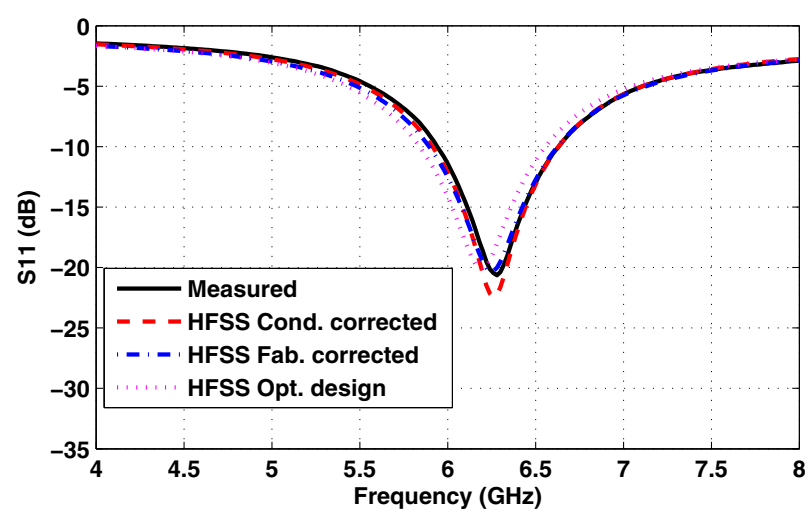

Figure 5: Simulated and measured S11 for a PEDOTpatch antenna on Ultralam $2000^{\mathrm{TM}}$ substrate

\begin{tabular}{|l|c|c|}
\hline \multicolumn{1}{|c|}{ CP Film } & \multicolumn{2}{|c|}{ Surface Resistivity $(\Omega / \bullet)$} \\
\hline & Measured (DC) & $\begin{array}{c}\text { Observed } \\
(6 \mathrm{GHz})\end{array}$ \\
\hline PPy $(90 \mu \mathrm{m})$ & 5.56 & 3 \\
\hline PEDOT $(7 \mu \mathrm{m})$ & 14.28 & 13 \\
\hline
\end{tabular}

Table 3: Surface resistivity of CP films.

The co-polarized radiation patterns of the PPy and PEDOT patch antennas and of the corresponding $\mathrm{Cu}$ patch antenna are shown in Figures 6 and 7 for the Eand H-plane. All patterns show a similar broadside shape (i.e. nearly identical directivities), but the different efficiencies explain different gain level. The IEEE gain and estimated radiation efficiency of the $\mathrm{Cu}$, PPy and PEDOT-microstrip patch antennas are listed in Table 4.

\begin{tabular}{|l|c|c|}
\hline \multicolumn{1}{|c|}{ Patch Type } & $\begin{array}{c}\text { Gain } \\
(\mathbf{d B})\end{array}$ & $\begin{array}{c}\text { Radiation Efficiency } \\
(\mathbf{\%})\end{array}$ \\
\hline $\mathrm{Cu}(17 \mu \mathrm{m})$ & 6 & 96.2 \\
\hline $\mathrm{PPy}(90 \mu \mathrm{m})$ & 3.8 & 48.16 \\
\hline PEDOT $(7 \mu \mathrm{m})$ & 2.2 & 33.63 \\
\hline
\end{tabular}

Table 4: Gain and radiation efficency of microstrip patch antennas. 


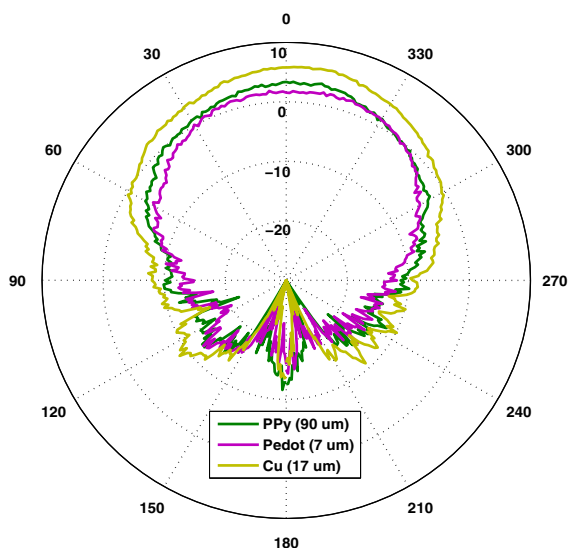

Figure 6: Measured E-plane co-pol antenna gain patterns.



Figure 7: Measured H-plane co-pol antenna gain patterns.

The radiation efficiency of the copper patch antenna was determined from measurement and simulation, while that of PPy and PEDOT-patch antennas was estimated by comparing the measured gain against that of the equivalent $\mathrm{Cu}$-patch antenna. The $\mathrm{Cu}$ patch antenna is resonant at $6.14 \mathrm{GHz}$ with a $-10 \mathrm{~dB}$ bandwidth of $236 \mathrm{MHz}$ or $3.8 \%$, while the PPy-patch antenna has a resonant frequency of $6.24 \mathrm{GHz}$ with a $-10 \mathrm{~dB}$ bandwidth of about $420 \mathrm{MHz}$ or $6.7 \%$ and the PEDOT-patch antenna has a resonant frequency of $6.28 \mathrm{GHz}$ with a $-10 \mathrm{~dB}$ bandwidth of about 700 $\mathrm{MHz}$ or $11 \%$.

\section{CONCLUSION}

The design of microwave antennas using CPs is challenging because producing $\mathrm{CP}$ films with thicknesses multiple times that of the skin depth is difficult using present manufacturing processes. Furthermore, the conductivity of CP films exhibits a dispersion that needs to be further investigated. The performance of CP-based $6 \mathrm{GHz}$ microstrip patch antennas was presented and compared an with equivalent $\mathrm{Cu}$ patch antenna. Despite, very low DC conductivities and thicknesses of the CP patches, reasonable antenna performance at microwave frequencies was observed with relatively low radiation efficiencies. The results clearly confirm the potential of polymer materials as antennas. Furthermore, since the electrical conductivity of CPs can be altered dynamically through external stimuli, it makes these antennas potentially very attractive despite their modest radiation efficiency.

\section{Acknowledgments}

The authors wish to acknowledge and thank Dr Leigh Powis (DSTO) for comments and suggestions and $\mathrm{Mr}$ Pavel Simcik (University of Adelaide) for fabrication of the antennas.

\section{References}

[1] N. R. Simons and R. Q. Lee, "Feasibility study of optically transparent microstrip patch antenna," Antennas and Propagation Society International Symposium 1997, vol. 4, pp. 21002103, 1997.

[2] S. Cichos, J. Haberland, and H. Reichl, "Performance analysis of polymer based antenna-coils for RFID," presented at IEEE Polytronic conference, 2002.

[3] H. Rmili, J. L. Miane, H. Zangar, and T. Olinga, "Design of microstrip fed proximity-coupled conducting polymer patch antenna," Microwave and Optical Technology letters, vol. 48, pp. 655660, 2006.

[4] N. J. Kirsch, N. A. Vacirca, E. E. Plowman, T. P. Kurzweg, A. K. Fontecchio, and K. R. Dandekar, "Optically transparent conductive polymer RFID meandering dipole antenna," presented at 2009 IEEE International Conference on RFID, Orlando, FL, 2009.

[5] A. Verma, C. Fumeaux, B. D. Bates, and V. T. Truong, "A 2GHz Polypyrrole Microstrip Patch Antenna on Plexiglas Substrate," Asia Pacific Microwave Conference 2009, pp. 36-9, 2009.

[6] V. T. Truong and J. G. Ternan, "Complex conductivity of a conducting polymer at microwave frequencies," Polymer, vol. 36, pp. 905-909, 1995.

[7] H. C. Starck: http://www.clevios.com, 20 May 2010.

[8] V. N. Prigodin and A. J. Epstein, "Quantum Hopping in metallic Polymers," Physica B, vol. 338, pp. 310-317, 2003.

[9] A. J. Epstein, Physical Properties of Polymers Handbook, vol. VIII. New York: Springer, 2007.

[10] H. C. F. Martens, J. A. Reedijk, H. B. Brom, D. M. de Leeuw, and R. Menon, "Metallic state in disordered quasi-one-dimensional conductors," Physical Review B, vol. 63, pp. 073203-1073203-4, 2001. 